\title{
The Effects of Narrative Perspectives and Gender Similarity to a Victim on Sympathy and Support for Aid to People in Need
}

\author{
Xiaoxia Cao \\ Correspondence: Xiaoxia Cao, University of Wisconsin-Milwaukee, United States \\ Received: January 30, 2014 Accepted: February 17, 2014 Available online: March 1, 2014 \\ doi:10.11114/smc.v2i1.329 \\ URL: http://dx.doi.org/10.11114/smc.v2i1.329
}

\begin{abstract}
An online experiment was conducted among a convenience sample of college students $(\mathrm{N}=219)$ to explore the effects of narrative perspectives (first-person vs. third-person) and gender similarity to a victim on sympathy and support for aid to people in need. To be specific, the study examined the influence of telling a story of an abused woman from a first-person perspective as opposed to a third-person perspective on participants' sympathetic reactions and their support for aid to abused women while considering the moderating role of gender similarity between the victim and participants.

The results of structural equation modeling showed the anticipated positive effects of gender similarity to the victim on sympathy and support for the aid. Gender similarity to the victim also interacted with narrative perspectives to influence support for the aid through affecting sympathy aroused for the victim. Specifically, telling the victim's experience from first-person as opposed to third-person perspectives had little impact on sympathy and the support among female participants but increased sympathy and, therefore, the support among male participants.

These findings shed light on how media portrayals of human suffering can increase aid to people in need. More importantly, they suggest how to call forth help via the media from people who are not normally inclined to support aid to those in need.
\end{abstract}

Keywords: narrative perspectives, similarity to a victim, gender, sympathy, support for aid

\section{Introduction}

Many people in the United States and around the world suffer from various issues (e.g., domestic violence and poverty) that deserve our attention and action. The media play a crucial role in conveying the needs of victims of these issues and elicit help for them because most people learn through the media about the suffering of others with whom they do not have direct contacts. One way to induce help for people in need through the media is to arouse sympathy for them because sympathy elicited for one victim prompts actions on behalf of the victim group as a whole (Batson, Chang, Orr, \& Rowland, 2002; Small \& Verrochi, 2009). Given that the impact of media coverage of human suffering varies depending upon exactly how the suffering is portrayed (Zillmann \& Brosius, 2000), it is important to know in what ways media portrayals of the suffering increase sympathy for those in need.

Telling a story from a first-person perspective (i.e., using direct quotes) has long been considered one of the key components of good news reports. According to textbooks of news reporting, personal testimony makes a story more believable, more natural sounding and more interesting (e.g., Mencher, 2010). In other words, personal testimony livens up the story. Although some studies have examined the effects of narrative perspectives (e.g., first-person vs. third-person) on perception of news quality, problem attributions, attitudes (Gibson \& Zillmann, 1998; de Graaf, Hoeken, Sanders, \& Beentjes, 2012) and decision making (Winterbottom, Bekker, Conner, \& Mooney, 2008), little is known about how telling a story of human suffering from first-person versus third-person perspectives may affect sympathy and support for aid to people in need, on the part of the audience, while keeping the content of the story constant.

Drawing on research into the effects of narrative perspectives, the construal level theory, the behavioral impact of sympathy, as well as the influence of similarity to people in need, this study explores the effects of first-person versus third-person narration on sympathy and support for aid to people in need while considering the moderating role played by gender similarity to those in need. The findings shed light on how media portrayals of human suffering may elicit aid for people in need.

\subsection{Conceptual Definitions: Narrative Perspectives and Sympathy}

When telling a story of a victim from a first-person perspective, the victim is the narrator himself/herself who reveals 
the story by referring to the viewpoint character as "I" (Card, 1988). In a third-person narrative, however, the narrator is merely an uninvolved person that tells the story of another person (i.e., a victim in the case of this study). The person is referred to by the narrator as "he," or "she." In other words, narrative perspectives (first-person vs. third-person) are determined by the relationship between the narrator and a victim. If the narrator is the victim, then the story is told from a first-person perspective. If the narrator is not the victim but an uninvolved person, then the story is recounted from a third-person perspective.

Although sympathy is sometimes used interchangeably with empathy, they are distinct concepts (Wispe, 1986). Sympathy refers to an emotional concern for the welfare of another person in distress, including experiencing feelings such as concern, compassion and pity for the person (e.g., Small \& Verrochi, 2009). Empathy, on the other hand, involves experiencing feelings parallel to those of another person. Using emotional reactions to the experience of an abused woman as an example, if one feels compassion for the woman, then s/he is experiencing sympathy. If, on the other hand, one feels hopeless, as the victim does, s/he experiences empathy. ${ }^{\mathrm{i}}$ The focus of the present study is sympathy felt for people in need.

\subsection{The Effect of Narrative Perspectives on Sympathy}

To understand a story, readers usually create a dynamic mental representation (or "situation model") of the states of affairs described in the story (Busselle \& Bilandzic, 2008; Kelter, Kaup, \& Clause, 2004). During the process, they take up a mental visual "vantage point" (Cohen, 2001). The perspective of narration (first-person or third-person) governs the mental visual perspective that readers take (Straiton, 2008). Specifically, first-person narration promotes a mental representation from an actor's perspective, whereas third-person narration furthers a representation from an observer's perspective (Brunyé, Ditman, Mahoney, Augustyn, \& Taylor, 2009; de Graaf et al., 2012).

Given the divergent mental visual perspectives adopted by readers of first-person versus third-person narratives, people may be more likely to view the world from the perspectives of characters when reading first-person narration as opposed to third-person narration (Busselle \& Bilandzic, 2008; Cohen, 2001). In other words, readers may be more inclined to travel with a character when the story is told from the perspective of the character as opposed to that of an observer. Indeed, a few studies have shown that people are more likely to put themselves in the shoes of a character, when reading first-person as opposed to third-person narration of the character's experience (de Graaf et al., 2012; Kaufman, 2009).

The perspective adopted by readers, when thinking about the experience of a character, in turn affects the psychological distance of the experience (Boven, Kane, McGraw, \& Dale, 2010) - defined as one's subjective perception that the experience is either close or remote (Trope \& Liberman, 2010; Trope, Liberman, \& Wakslak, 2007). Consistent with this argument, studies found that participants who were asked to imagine a dentist visit from a patient's eyes as opposed to an observer's eyes considered the visit psychologically closer (Boven et al., 2010). Similarly, they perceived a performance to be closer when asked to think about the performance from a first-person versus a third-person perspective.

The decreased psychological distance of described events-induced by adopting the perspective of a character, as a result of exposure to a first-person narrative - may then heighten the sympathetic reactions of readers. According to the construal level theory, the psychological distance of events influences one's mental representations of the events such that psychologically distant events are represented in terms of a few abstract features that define the events (high-level construals), whereas psychologically near events are represented in terms of concrete and incidental details (low-level construals; Trope et al., 2007). In other words, as the psychological distance of a described event increases, a concrete and detailed mental representation of the event is increasingly replaced by a more abstract one. Corroborating this reasoning, research has shown that, even when provided with the same information about psychologically close and distant events, people tend to represent the former in more concrete and detailed terms in their mind (Fujita, Henderson, Eng, Trope, \& Liberman, 2006). A concrete and vivid representation should be more emotionally arousing (e.g. in terms of induced sympathy) than an abstract one (Loewenstein \& Small, 2007; Zillmann \& Broius, 2000).

Taken together, although no studies have directly tested how telling a victim's story from a first-person versus a third-person perspective may influence sympathy felt for the victim, the current literature suggests that first-person narratives should arouse greater sympathy for victims than third-person narratives. This is because first-person narration tends to motivate readers to adopt the perspective of a victim, feel psychologically close to the victim's experience, and, thus, sympathize with the victim.

\subsection{The Impact of Sympathy}

According to Batson and his colleagues (2002), sympathy felt for one member of a group leads to increased care for the group as a whole, as long as the group identity is considered a salient component of the situation toward which sympathy is evoked. The increased valuing of the group's welfare produces more aid to the group. In line with this reasoning, many studies have found a link between sympathy and helping behavior (Batson et al., 2002; Clore \& Jeffery, 1972; Small \& Verrochi, 2009). Of particular importance, the positive behavioral impact of sympathy may last long 
after the feeling has disappeared (Batson et al., 1997; Clore \& Jeffery, 1972). For example, in one study, participants expressed strong support for spending student funds on facilities for disabled students four months after sympathy for disabled students was evoked (Clore \& Jeffrey, 1972). The finding suggests that first-person narration of a victim's experience should produce more support for aid to the victim group than third-person narration because of its ability to arouse greater sympathy for the victim.

\subsection{The Moderating Role of Gender Similarity to a Victim}

Similarity to a victim compels readers to sympathize with and help the victim because it affects the degree to which the readers think what happens to the victim may be personally relevant (Davis, 1996; Gueguen, Pichot, \& Le Dreff, 2005; Loewenstein \& Small, 2007; Levine, Prosser, Evans, \& Reicher, 2005; Trope et al., 2007). Arguably, there is more than one dimension on which similarity between readers and a victim can rest. Given that this study tests the effects of narrative perspectives and similarity of readers to a victim using a story about a battered wife, gender is likely a salient trait on which the readers judge their similarity to the victim. Hence, the present study focuses on the effect of gender similarity between the readers and the victim. Because of their gender similarity to abused women, female readers should be more likely than male readers to sympathize with and, thus, support aid for the victims.

Moreover, gender similarity to a victim may interact with narrative perspectives to influence sympathy and support for aid to victims. However, it is unclear exactly how the two factors may interact with one another. On one hand, because gender similarity to a victim tends to have positive effects on sympathy and support for aid, telling a victim's story from a first-person versus a third-person perspective may not exert as much influence on readers who are similar to the victim as on those who are dissimilar to the victim. On the other hand, it is possible that gender similarity to a victim accentuates the expected positive effects of first-person narratives on sympathy and support for aid.

Given that the predicted positive impacts of first-person (vs. third-person) narratives and gender similarity to a victim on support for aid should be at least partly explained by their positive effects on sympathy (Davis, 1996; Loewenstein \& Small, 2007), I anticipate that the interaction effect of narrative perspectives and gender similarity to a victim on the support, if there is any, will also be at least partly mediated by sympathy felt for the victim. For this reason, the present study tests not only the direct interaction effects of narrative perspectives and gender similarity to a victim on sympathy and support for aid but also the indirect interaction effect of the two factors on the support via sympathy.

\subsection{An Integrated Model}

Figure 1 shows a predictive model being tested in this study. According to the model, first-person as opposed to third-person narratives are expected to arouse greater sympathy and increase support for aid to victims. Given that this study uses a story about an abused woman to test the model, gender similarity to the victim is measured by participants' gender such that female subjects are considered similar to the victim whereas male subjects are dissimilar to the victim. As indicated in the model, gender similarity to the victim is expected to have positive effects on sympathy and support for the aid. Moreover, gender similarity to the victim may interact with narrative perspectives (first person vs. third-person) to influence sympathy and the support. Finally, the model predicts that the effect of the two factors (i.e., narrative perspectives and gender similarity to the victim) and the interaction effect between the two on the support are at least partly mediated by sympathy felt for the victim.

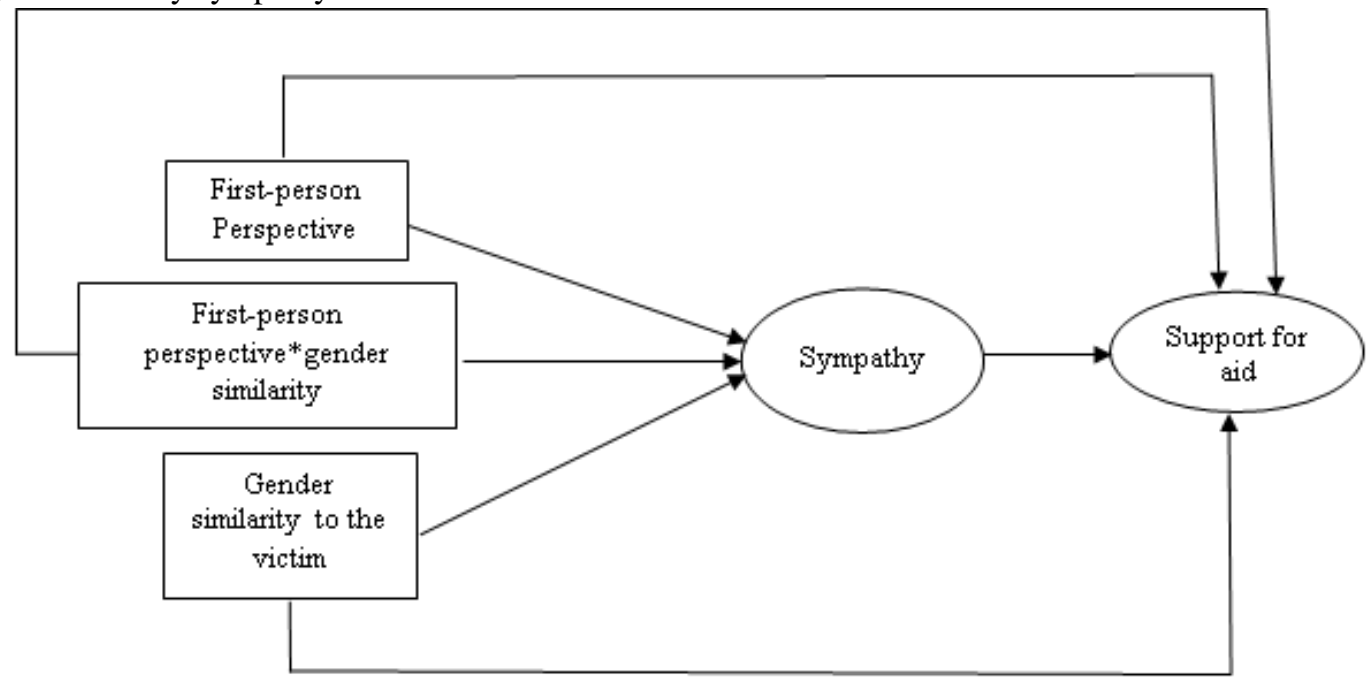

Figure 1. A predictive model of the effects of narrative perspectives (first-person vs. third-person), gender similarity to a victim and the interaction between the two on sympathy and support for aid 


\section{Method}

To test the model, an online experiment was conducted among students at a public university in the Midwestern United States. It had a 2 (narrative perspective: first-person vs. third-person) X 2 (gender similarity to the victim: similar vs. dissimilar) between-subject design.

\subsection{Material}

Each participant read a story about Mary whose husband kept her under surveillance 24/7. He would call her horrible names and beat her if he found her going out with family or friends, or talking with someone. He would not stop beating her while she was pregnant. Because of it, she lost her baby. When she told him she wanted to leave, he threatened to kill her and her family. One night, after getting her husband drunk, Mary called her friend who brought her to a shelter. Upon arriving at the shelter, Mary was told that she could only stay for a few days because there was not enough room, even though she had no place to go. She did not want her family and friends to get hurt because of her, so she could not stay with them. She could not go back to home either because her husband was going to kill her.

Mary's story was created based upon personal stories of abused women (that were obtained from the websites of organizations that help battered women). The story began with telling readers that Mary was safe for the moment because she was residing at a shelter. When arriving at the shelter, she told a staff member her experience. The experience was then told either from Mary's perspective (i.e., a first-person perspective) or from the staff member's perspective (i.e., a third-person perspective). For example, when the story described how Mary was abused by her husband, the first-person narrative reads "If he found me going out with my family or friends, or talking with someone, he would get angry, call me horrible names, slap my face, twist my wrist, shove me to the ground and bang my head against the floor," whereas the third-person narration reads "If he found her going out with her family or friends, or talking with someone, he would get angry, call her horrible names, slap her face, twist her wrist, shove her to the ground and bang her head against the floor." Except the difference in the narrative perspectives, the two versions of the story were identical.

\subsection{Participants}

Two hundred and nineteen college students (recruited from entry-level communication courses) participated in the study in exchange for extra credit. Thirty-eight students who either skipped Mary's story or did not complete the study were excluded from the analysis. ${ }^{i i}$ The remaining 181 participants had a mean age of $21.07(S D=3.44)$. Sixty-nine percent of them were female and $31 \%$ were male. In terms of race, the majority of them were white Americans (82\%), followed by Hispanic Americans (6\%), African Americans (4\%) and Asian Americans (3\%). The rest of participants (5\%) were mixed race or other.

\subsection{Procedure}

Participants were directed to the webpage of this study through a link distributed via email. Once they got to the webpage, they were provided with information about the study and, then, asked to decide whether or not they were willing to participate. After giving informed consent, subjects were randomly assigned to one of the two narrative-perspective conditions. Before reading Mary's story, each participant completed a questionnaire that measured demographics (age, gender and race) and individual tendencies to experience sympathy and take the perspective of others. These tendencies were assessed by the subcomponents of the Interpersonal Reactivity Index (see Davis, 1980 for question wording). ${ }^{\text {iii }}$ After reading the story, participants answered a series of questions measuring sympathy and support for aid to abused women.

\subsection{Measures}

Sympathy was tapped by five items adapted from commonly used measures (e.g., Batson et al., 2002; Small \& Verrochi, 2009). They asked subjects to rate on a 7 -point scale $(1=$ not at all; $7=$ extremely) the extent to which they experienced a series of emotions (e.g., compassion and concern) for the victim, when reading the story.

Given that aid to victims can come in the form of government programs/interventions that benefit the victims and/or support from charitable organizations, attitudes toward aid to abused women were measured by asking participants about their support for government programs/interventions (that benefit abused women) and their intentions to assist in increasing funding for charities that help abused women. Specifically, the measure asked participants to rate each of the following statements on a 7 -point agreement scale $(1=$ strongly disagree; 7 = strongly agree): (1) "Law enforcement should do more to prevent domestic violence from happening"; (2) "Law enforcement should do more to prosecute those who engage in domestic violence"; (3) "The government should provide more support for abused women"; (4) "The government should allocate more money to support abused women"; (5) "The government does not need to do more than it already does to support abused women"(reverse-worded); (6) "I'm willing to help abused women by donating money to charities that protect abused women through building more shelters and/or providing legal service"; 
(7) "I'm willing to help abused women by asking people that I know to donate money to charities that protect abused women" (see Table 1 for descriptive statistics and correlations of variables/items involved in the analyses).

Table 1. Descriptive statistics and correlations

\begin{tabular}{|c|c|c|c|c|c|c|c|c|c|c|}
\hline Variables/Items & 1 & 2 & 3 & 4 & 5 & 6 & 7 & 8 & 9 & 10 \\
\hline $\begin{array}{l}\text { 1. Narrative } \\
\text { perspectives (first }=1 \text {; } \\
\text { third }=0 \text { ) }\end{array}$ & -- & & & & & & & & & \\
\hline $\begin{array}{l}\text { 2. Gender similarity } \\
(\text { female }=1 ; \text { male }=0)\end{array}$ & .03 & -- & & & & & & & & \\
\hline $\begin{array}{l}\text { 3. Perspective } X \\
\text { similarity }\end{array}$ & .01 & .00 & -- & & & & & & & \\
\hline \multicolumn{11}{|l|}{$\begin{array}{l}\text { Items used to measure } \\
\text { sympathy }\end{array}$} \\
\hline 4. Sympathy1 & .11 & $.17^{*}$ & $-.13^{\#}$ & -- & & & & & & \\
\hline 5. Sympathy2 & .03 & $.27 * *$ & -.12 & $.70 * *$ & -- & & & & & \\
\hline 6. Sympathy3 & .05 & $.19 *$ & -.12 & $.52 * *$ & $.71 * *$ & -- & & & & \\
\hline 7. Sympathy4 & -.02 & $.15^{*}$ & $-.15^{\#}$ & $.52 * *$ & $.56^{* *}$ & $.48 * *$ & -- & & & \\
\hline 8. Sympathy5 & -.02 & $.22 * *$ & -.10 & $.71 * *$ & $.83^{* *}$ & $.62 * *$ & $.64 * *$ & -- & & \\
\hline \multicolumn{11}{|l|}{$\begin{array}{l}\text { Items used to measure } \\
\text { support for aid }\end{array}$} \\
\hline 9. Support1 & .12 & $.20 * *$ & -.12 & $.36^{* *}$ & $.50^{* *}$ & $.41 * *$ & $.28 * *$ & $.42 * *$ & -- & \\
\hline 10. Support2 & .05 & .03 & -.08 & $.28 * *$ & $.33 * *$ & $.26 * *$ & $.20 * *$ & $.27 * *$ & $.56^{* *}$ & -- \\
\hline 11. Support3 & .10 & $.34 * *$ & -.08 & $.36^{* *}$ & $.47 * *$ & $.32 * *$ & $.28 * *$ & $.41 * *$ & $.72 * *$ & $.48 * *$ \\
\hline 12. Support4 & $.13^{\#}$ & $.30^{* *}$ & -.06 & $.40^{* * *}$ & $.46^{* *}$ & $.31 * *$ & $.29 * *$ & $.41 * *$ & $.63^{* *}$ & $.42 * *$ \\
\hline 13. Support5 & .01 & $.31^{* *}$ & -.05 & $.25^{* *}$ & $.41^{* *}$ & $.28 * *$ & $.25^{* *}$ & $.33^{* *}$ & $.45^{* *}$ & $.23 * *$ \\
\hline 14. Support6 & .04 & $.27 * *$ & $-.14^{\#}$ & $.29^{* *}$ & $.32^{* *}$ & $.17^{*}$ & $.22 * *$ & $.32 * *$ & $.33^{* *}$ & $.27 * *$ \\
\hline 15. Support7 & .12 & $.28^{* *}$ & $-.13^{\#}$ & $.22 * *$ & $.28 * *$ & $.17^{*}$ & $.24 * *$ & $.28 * *$ & $.37 * *$ & $.27 * *$ \\
\hline$M$ & .51 & .69 & .01 & 6.23 & 6.32 & 6.28 & 6.52 & 6.15 & 6.03 & 6.22 \\
\hline$S D$ & .50 & .47 & .23 & 1.06 & .91 & .98 & .78 & 1.04 & 1.03 & 1.06 \\
\hline
\end{tabular}

Note: Table entries are zero-order correlation coefficients; ${ }^{\#} p<.10 ; * p<.05 ; * * p<.01$.

Table 1. Descriptive statistics and correlations (continued)

\begin{tabular}{lccccc}
\hline Variables/Items & 11 & 12 & 13 & 14 & 15 \\
\hline 11. Support4 & -- & & & & \\
12. Support5 & $.79^{* *}$ & -- & & & \\
13. Support6 & $.58^{* *}$ & $.55^{* *}$ & -- & & \\
14. Support7 & $.49^{* *}$ & $.46^{* *}$ & $.32^{* *}$ & -- & \\
15. Support8 & $.27^{* *}$ & $.47^{* *}$ & $.33^{* *}$ & $.77^{* *}$ & -- \\
M & 6.09 & 5.71 & 5.73 & 5.54 & 5.46 \\
SD & 1.02 & 1.26 & 1.21 & 1.21 & 1.29 \\
\hline
\end{tabular}

Note: Table entries are zero-order correlation coefficients; ${ }^{\#} p<.10 ; * p<.05 ; * * p<.01$.

\subsection{Analysis Strategy}

The structural equation modeling (SEM) was used to test the model presented in Figure 1. To create an interaction term between narratives perspectives and gender similarity to the victim, I centered and multiplied two variables: narrative perspectives (first-person $=1$; third-person $=0$ ) and participants' gender (female $=1$; male $=0$ ). An inspection of the univariate distribution of all observed variables revealed that all variables are normally distributed according to the criteria of $\mid$ skewness $\mid<2$ and $\mid$ Kurtosis $\mid<7$ (West, Finch, and Curran, 1995). The largest skewness value in the data was -1.95 and the largest Kurtosis value was 4.88. Hence, ML estimation in Mplus was used.

Given that sympathy and support for aid to abused women were measured by multiple items, these variables were 
treated as latent variables. To test the proposed model, I took a two-step approach by first establishing the adequacy of the measurement component and then estimating the model as a whole. Model fit was evaluated mainly using three indicators: Chi-square $\left(\chi^{2}\right)$ test of model fit, comparative fit index (CFI) and root means square error of approximation (RMSEA). Because there is evidence that women are more likely than men to sympathize with and take the perspectives of others (Eagly \& Crowley, 1986; McGowen \& Hart, 1990), one's sympathy and perspective taking tendencies were included in the analysis as control variables to disentangle the effects of gender similarity from those of women's greater tendencies to experience sympathy and take others' perspectives.

\section{Results}

Because the tested model included two latent variables, I first estimated a measurement model. The model included five indicators of sympathy and seven indicators of support for aid to abused women, and the two latent variables. The latent variables were allowed to covary. Five error correlations were added based upon the results of preliminary analyses. ${ }^{\text {iv }}$ The estimation of the modified measurement model indicated adequate fit to the data $\left(\chi^{2}(48, N=178)=46.37, p=.54\right.$, $\mathrm{CFI}=1.00$, RMSEA $=.00,90 \% \mathrm{CI}$ of RMSEA $=.00-.05)$. The parameter estimates showed that the factor loadings in the modified measurement model ranged from .52 to .97 , all higher than the traditional .40 cutoff value.

After establishing the adequacy of the measurement model, I proceeded to test the proposed model including the hypothesized direct and indirect effects with individual tendencies to experience sympathy and take others' perspectives as control variables. The indicators of model fit showed that the model was consistent with the data $\left(\chi^{2}(88, N=175)=\right.$ 95.12; $p=.28 ; \mathrm{CFI}=1.00 ; \mathrm{RMSEA}=.02 ; 90 \% \mathrm{CI}$ of RMSEA $=.00-.05)$. The results of model estimation are shown in Figure 2. For the purpose of clarity, (marginally) significant relationships are represented by solid lines and non-significant relationships are indicated by dashed lines.

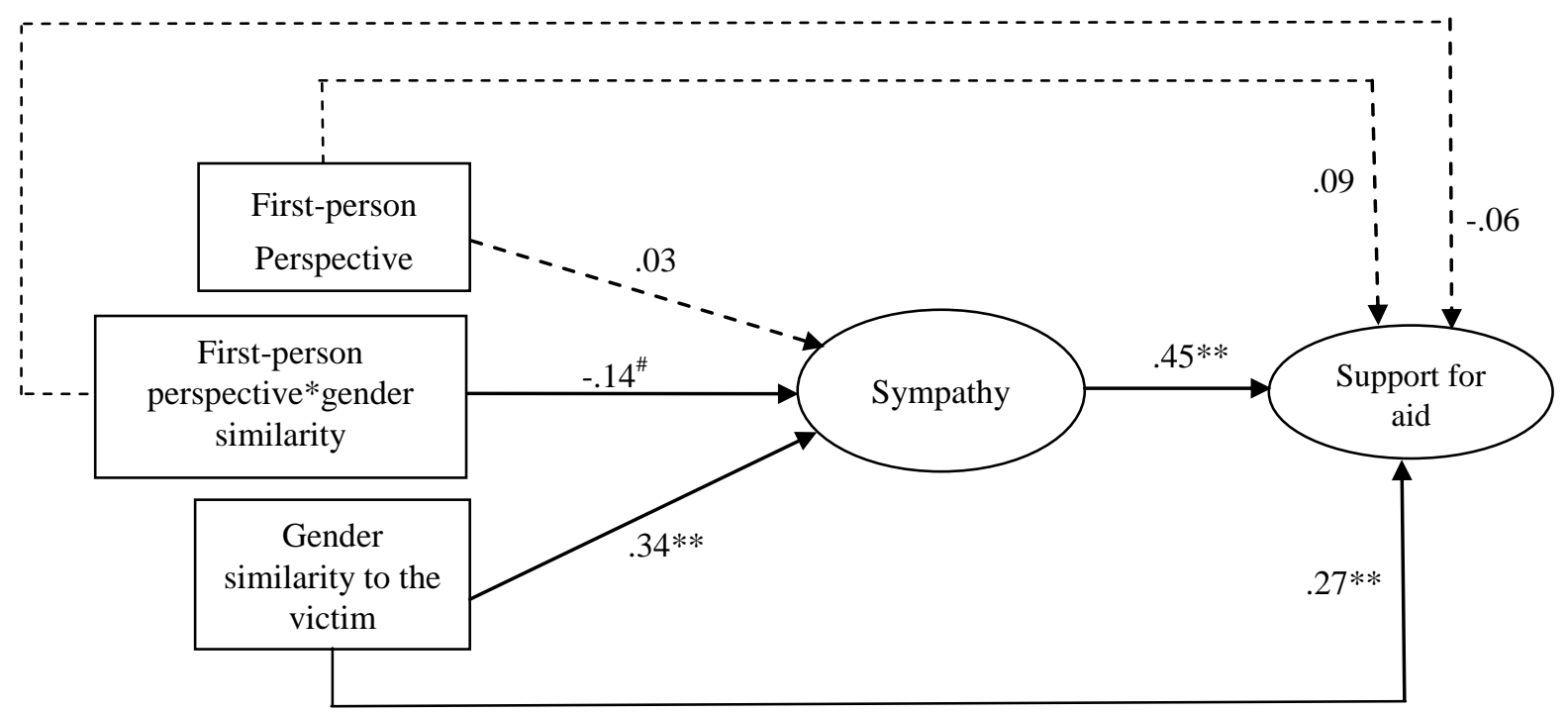

Note: all numbers are standardized regression coefficients; ${ }^{\#} p=.05 ; * * p<.01$; gender similarity to the victim was measured by participants' gender with female being coded as 1 and male as 0 ; individual tendency to experience sympathy and take the perspectives of others were included as control variables in the analysis.

Figure 2. Model estimation results

The analysis did not find significant positive effects of first-person narratives (as opposed to third-person narratives) on sympathy $(\beta=.03, p=.70)$ or support for the aid $(\beta=.09, p=.17)$. Gender similarity to the victim, however, had anticipated direct positive effects on sympathy $(\beta=.34, p<.01)$ and the support $(\beta=.27, p<.01)$. Moreover, the model estimation indicated a marginally significant negative interaction effect of first-person (vs. third-person) narratives and gender similarity to the victim on sympathy $(\beta=-.14, p=.05)$ but no significant interaction effect of the two on the support $(\beta=-.06, p=.33)$. Further analyses indicated that telling the victim's story from first-person as opposed to third-person perspectives had little impact on sympathy experienced by female participants $(p=.93 ; d=.14)$ but increased sympathy felt by male participants $(p<.01 ; d=.50$; see Figure 3$)$. In addition, the analysis found an anticipated positive relationship between sympathy and the support $(\beta=.45, p<.01)$. 


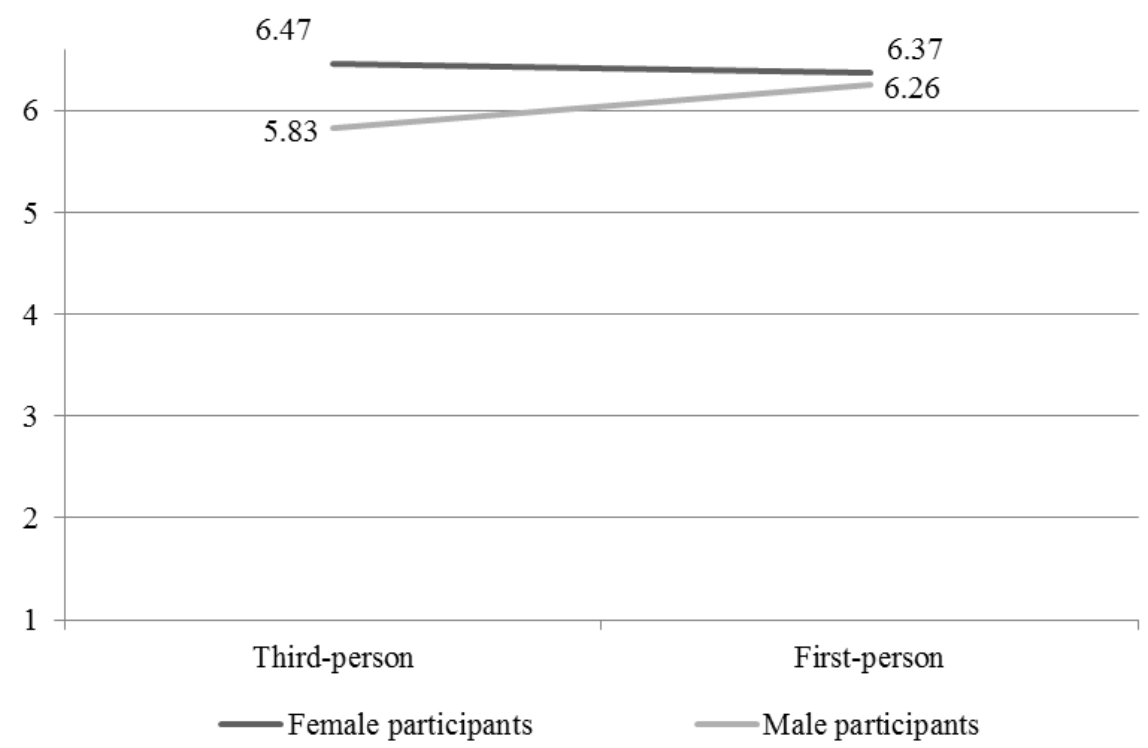

Figure 3. An interaction effect of narrative perspectives (first-person vs. third-person) and gender similarity to the victim on sympathy

Turning to the test of indirect effects, the analysis showed a significant indirect effect of gender similarity $(\beta=.16, p$ $<.01)$ and a marginally significant indirect interaction effect of narrative perspectives and gender similarity $(\beta=-.07, p$ $=.06$ ) on support for the aid via sympathy felt for the victim. Follow-up analyses showed that telling the victim's experience from a first-person perspective as opposed to a third-person perspective increased the support among male participants $(p=.04 ; d=.56)$ but had little impact among female participants $(p=.89 ; d=.03$; see Figure 4). Altogether, the total variance explained by the full model was $13 \%$ for sympathy and $37 \%$ for support for the aid.

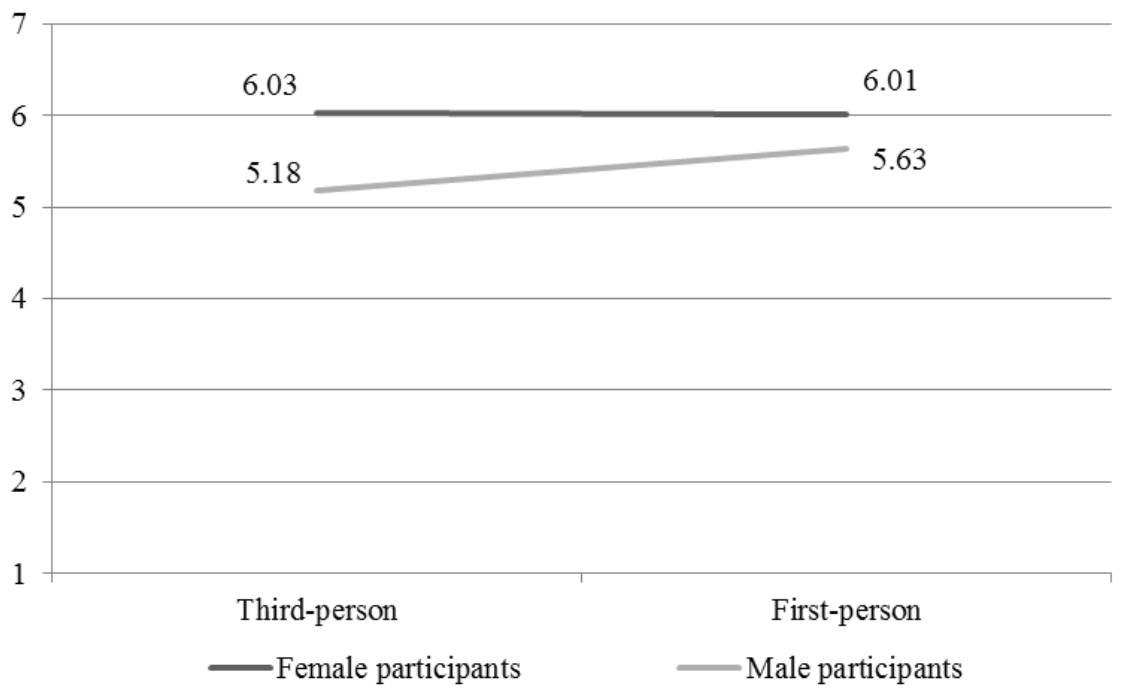

Figure 4. An interaction effect of narrative perspectives (first-person vs. third-person) and gender similarity to the victim on support for aid

\section{Discussion}

The media play an important role in eliciting aid for those in need. Given that one tends to offer help to others with whom s/he sympathizes, this study examined in what way and under what circumstances media portrayals of human suffering increase sympathy and support for aid to people in need. More specifically, the present study investigated the effects of narrative perspectives (first-person vs. third-person) on sympathy and support for aid to abused women while considering the moderating role of gender similarity to the victims. Inconsistent with the proposed model (see Figure 1), the study did not find predicted positive effects of first-person versus third-person narration on sympathy or support for 
the aid. The lack of the expected effects of first-person narration on the outcome variables under study suggests that telling a victim's story from a first-person as opposed to a third-person perspective may not have uniform impacts on readers. Rather, its impacts may vary depending upon other factors (e.g., similarity between readers and the victim). Indeed, my analysis found that the effects of narrative perspectives (first-person vs. third-person) on sympathy and support for the aid varied depending upon participants' gender similarity to the victim such that first-person narration increased sympathy and the support among male participants (i.e., participants dissimilar to the victim in terms of gender) but had little impact among female participants (i.e., participants similar to the victim). Moreover, the observed interaction effect of narratives perspectives and gender similarity to the victim on the support was mediated by sympathy felt for the victim.

As anticipated, even after controlling for greater tendencies of women than men to sympathize with and take the perspectives of others, gender similarity to the victim had direct positive effects on sympathy and support for the aid. The observed positive effect of gender similarity to the victim on the support was partly explained by sympathy felt for the victim. These findings are consistent with previous studies showing that similarity to a victim motivates people to sympathize with and help the victim (Davis, 1996; Gueguen et al., 2005; Loewenstein \& Small, 2007; Levine et al., 2005; Trope et al., 2007).

Several strengths and weaknesses of this study should be kept in mind while drawing conclusions from the results presented here. Beginning with the strengths, the experimental nature of the study allowed me to infer that the observed relationships between the interaction of narrative perspectives and gender similarity to the victim, on one hand, and sympathy and support for aid to abused women, on the other hand, are causal ones. Moreover, by keeping the content of the story constant across the two narrative-perspective conditions, I was able to attribute the observed positive effects of first-person narratives on sympathy and support for the aid among male participants to the narrative perspectives used to recount the victim's experience.

As for the limitations, this study did not include a control condition. Hence, it is unclear how exposure to the victim's story accounted from different narrative perspectives may affect support for the aid relative to no exposure. Moreover, the study used an issue particularly relevant to women - domestic violence - to test the effect of gender similarity to a victim and the interaction effect of narrative perspectives and gender similarity to a victim on sympathy and support for aid to people in need. Further research could test the effects of narrative perspectives and gender similarity to a victim using different issues. Such research could also test how similar to a victim in terms of other traits (e.g., age or race) may affect one's responses. Finally, the study was conducted among a convenience sample of college students. Future studies could test the effect of narrative perspectives and similarity to victims on support for aid to those in need using a more representative sample.

Despite these limitations, the findings of this study have a number of implications. The observation that first-person as opposed to third-person narration aroused greater sympathy among a subgroup of participants contributes to our understanding of how media portrayals of human suffering may increase sympathy for people in need. The observation also partly supports the argument that first-person (vs. third-person) narration of a victim's experience motivates readers to sympathize with the victim and, thus, support aid for the victim because it compels the readers to adopt the perspective of the victim and, therefore, feel psychologically close to the victim's experience. Beyond this, the finding that the effect of gender similarity to the victim and the interaction effect of narrative perspectives and gender similarity on support for the aid were (partly) explained by sympathy felt for the victim supports the notion that sympathy is a pathway to elicit aid for those in need (Batson, 2011; Clore \& Jeffery, 1972; Small \& Verrochi, 2009).

More importantly, my findings indicate that compared with third-person narration of a victim's experience, first-person narration may produce more sympathy and support for aid to victims among the subgroup of the audience that is not normally inclined to sympathize with and help the victims due to various differences between the audience and the victims (e.g., differences in gender, race and nationality). This is because the present study found that telling a story about an abused woman from a first-person versus a third-person perspective induced greater sympathy and support for aid to abused women among male participants. In fact, the first-person narration brought levels of male participants' sympathy and support for the aid closer to those of female participants' (see Figure 3 and Figure 4).

Eliminating the chronic threats to the survival and welfare of human beings dictates the actions of individuals, organizations and governments around the world. People with resources do not necessarily feel obliged to offer help sometimes because they consider those in need "others" not "us" due to various differences between the former and the latter groups. My finding of positive effect of first-person narration of an abused woman's experience on support for aid to abused women among male participants indicates that telling the story of a victim from first-person perspective might help to break through social and cultural boundaries and elicit aid for those in need from out-group members and people from another country. 
Given that the media play a crucial role in conveying the needs of others to people with resources to help, it is imperative to understand how media portrayals of human suffering could motivate the latter to offer help to the former despite the social and cultural differences between them. The findings of the present study not only suggest one possible way to do so but also call for future studies on this topic.

\section{References:}

Batson. C. D. (2011). Altruism in humans. New York, NY: Oxford University Press.

Batson, C. D., Chang, J., Orr, R., \& Rowland, J. (2002). Empathy, attitudes, and action: Can feeling for a member of a stigmatized group motivate one to help the group. Personality and Social Psychology Bulletin, 28(12), 1656-1666. http://dx.doi.org/10.1177/014616702237647

Batson, C. D., Polycarpou, M. P., Harmon-Jones, E., Imhoff, H. J., Mitchener, E. C., Bednar, L. L., Klein, T. R., \& Highberger, L. (1997). Empathy and attitudes: Can feeling for a member of a stigmatized group improve feelings toward the group? Journal of Personality and Social Psychology, 72(1), 105-118. http://dx.doi.org/10.1037/0022-3514.72.1.105

Busselle, R., \& Bilandzic, H. (2008). Fictionality and perceived realism in experiencing stories: A model of narrative comprehension and engagement. Communication Theory, 18(2), 255-280. http://dx.doi.org/10.1111/j.1468-2885.2008.00322.x

Boven, L. V., Kane, J., McGraw, A. P., \& Dale, J. (2010). Feeling close: Emotional intensity reduces perceived psychological distance. Journal of Personality and Social Psychology, 98(6), 872-885. http://dx.doi.org/10.1037/a0019262

Brunyé, T. T., Ditman, T., Mahoney, C. R., Augustyn, J. S., \& Taylor, H. A. (2008). When you and I share perspectives: Pronouns modulate perspective taking during narrative comprehension, Psychological Science, 20(1), 27-32. http://dx.doi.org/10.1111/j.1467-9280.2008.02249.x

Card, O. S. (1998) Characters and viewpoint. Cincinnati, OH: Writer's Digest Books.

Clore, G. L., \& Jeffery, K. M. (1972). Emotional role playing, attitude change, and attraction toward a disabled person. Journal of Personality and Social Psychology, 23(1), 105-111. http://dx.doi.org/10.1037/h0032867

Cohen, J. (2001). Defining identification: A theoretical look at the identification of audiences with media characters. Mass Communication \& Society, 4(3), 245-264. http://dx.doi.org/10.1207/S15327825MCS0403_01

Davis, M. H. (1980). A multidimensional approach to individual differences in empathy. JSAS Catalog of Selected Documents in Psychology, 10, 85. Retrieved from http://www.uv.es/ friasnav/Davis_1980.pdf

Davis, M. H. (1996). Empathy: A social psychological approach. Boulder, CO: the Westview Press, Inc.

De Graaf, A., Hoeken, H., Sanders, J., \& Beentjes, J. W. J. (2012). Identification as a mechanism of narrative persuasion. Communication Research, 39(6). http://dx.doi.org/10.1177/0093650211408594

Eagly, A. H., \& Crowley, M. (1986). Gender and helping behavior: A meta-analytic review $\mathrm{f}$ the social psychological literature. Psychological Bulletin, 100(3), 283-308. http://dx.doi.org/10.1037/0033-2909.100.3.283

Fujita, K., Henderson, M., Eng, J., Trope, Y., \& Liberman, N. (2006). Spatial distance and mental construal of social events. Psychological Science, 17(4), 278-282. http://dx.doi.org/10.1111/j.1467-9280.2006.01698.x

Gibson, R., \& Zillmann, D. (1998). Effects of citation in exemplifying testimony in issue perception. Journalism and Mass Communication Quarterly, 75(1), 167-176.

Gueguen, N., Pichot, N., \& Le Dreff, G. (2005). Similarity and helping behavior on the web: The impact of the convergence of surnames between a solicitor and a subject in a request made by e-mail. Journal of Applied Social Psychology, 35(2), 423-429. http://dx.doi.org/10.1177/0146167204271651

Kaufman, G. F. (2009). Down the rabbit hole: Exploring the antecedents and consequences of identification with fictional characters (Doctoral dissertation). Retrieved from OhioLINK ETD Center. Document number: osu1259601597.

Kelter, S., Kaup, B., \& Claus, B. (2004). Representing a described sequence of events: A dynamic view of narrative comprehension. Journal of Experimental Psychology: Learning, Memory and Cognition, 30(2), 451-464. http://dx.doi.org/10.1037/0278-7393.30.2.451

Loewenstein, G., \& Small, D. A. (2007). The scarecrow and the tin man: The vicissitudes of human sympathy and caring. Review of General Psychology, 11(2), 112-126. http://dx.doi.org/10.1037/1089-2680.11.2.112. 
Levine, M., Prosser, A., Evans, D., \& Reicher, S. (2005). Identity and emergency intervention: How social group membership and inclusiveness of group boundaries shape helping behavior. Personality and Social Psychology Bulletin, 31(4), 443-453. http://dx.doi.org/10.1177/0146167204271651

McGowen, K. R., \& Hart, L. E. (1990). Still different after all these years: Gender differences in professional identity formation. Professional Psychology: Research and Practice, 21(2), 118-123. http://dx.doi.org/10.1037/0735-7028.21.2.118

Mencher, M. (2010). Melvin Mencher's News Reporting and Writing (12 $2^{\text {th }}$ ed.). New York, NY: McGraw-Hill.

Small, D. A., \& Verrochi, N. M. (2009). The face of need: Facial emotion expression on charity advertisements. Journal of Marketing Research, 46(6), 777-787. http://dx.doi.org/0.1509/jmkr.46.6.777

Straiton, A. (2008). 'I have my tricks and trap doors too': Double deixis, reader investment and self-identification in literature and popular music. INNERVATE Leading Undergraduate Work in English Studies, 1, 285-300.

Trope, Y., \& Liberman, N. (2010). Construal-level theory of psychological distance. Psychological Review, 117(2), 440-463. http://dx.doi.org/10.1037/a0018963

Trope, Y., Liberman, N., \& Wakslak, C. (2007). Construal levels and psychological distance: Effects on representation, prediction, evaluation and behavior. Journal of Consumer Psychology, 17(2), 83-95. http://dx.doi.org/10.1080/10577400701242227

West, S. G., Finch, J. F., \& Curran, P. J. (1995). Structural equation models with nonnormal variables: Problems and remedies. In R. H., Hoyle (Ed.). Structural equation modeling: Concepts, issues, applications (pp. 56-75). Thousand Oaks, CA: Sage.

Winterbottom, A., Bekker, H. L., Conner, M., \& Mooney, A. (2008). Does narrative information bias individual's decision making? A systematic review. Social Science \& Medicine, 67, 2079-2088. http://dx.doi.org/10.1016/j.socscimed.2008.09.037

Wispe, L. (1986). The distinction between sympathy and empathy: To call forth a concept, a word is needed. Journal of Personality and Social Psychology, 50(2), 314-321. http://dx.doi.org/10.1037/0022-3514.50.2.314

Zillmann, D., \& Brosius, H. B. (2000). Exemplification in communication: The influence of case reports on the perception of issues. Mahwah, NJ: Lawrence Erlbaum Associates.

\footnotetext{
i Some scholars (e.g., Batson) have used the term "empathic concern" to label one's sympathetic reactions to others' distress. For the purpose of consistency and clarity, the term "sympathy" is used to refer to one's emotional concern for the welfare of another person throughout the paper, regardless of the term used by other scholars in their work.

ii The experiment was conducted using Qualtrics, an online survey software. The software creates a variable that indicates whether or not a participant completed a study. It also enables researchers to secretly record the amount time spent by a participant on a webpage. Based upon the information provided by Qualtrics, 29 participants did not complete the experiment and 9 skipped the victim's story (i.e., spending less than 20 seconds on the webpage with a 484-word story about Mary).

iii An index of perspective taking tendencies $(M=5.27 ; S D=.91$; Cronbach's Alpha $=.85)$ was created by average each participant's scores on the seven items used to measure the tendencies. The same method was used to create an index of individual tendencies to experience sympathy $(M=5.78 ; S D=.72 ;$ Cronbach's Alpha $=.82)$.

iv The error correlations of the following pairs were allowed in the final measurement model: sympathy1 and 2, sympathy 1 and 4 , sympathy 4 and 5 , support 1 and 2 , as well as support6 and 7 .
}

\section{(cc) $\mathrm{EY}$}

This work is licensed under a Creative Commons Attribution 3.0 License. 